DOI : 10.25273/florea.v8i2.9746

\title{
KEANEKARAGAMAN MIKROALGA DI BENDUNGAN BARATA DESA E.WONOKERTO KABUPATEN MUSI RAWAS
}

\author{
Dian Selviana ${ }^{1)}$, Harmoko ${ }^{2 *}$ dan Destien Atmi Arisandi ${ }^{3)}$ \\ ${ }^{1,2,3)}$ Pendidikan Biologi STKIP PGRI Lubuklinggau \\ 2Email: putroharmoko@gmail.com
}

Naskah diterima, dan disetujui (diisi oleh tim redaksi, TNR-11, bold, rata tengah)

\begin{abstract}
This study aims to determine the diversity of microalgae in the Barata Dam area, E. Wonokerto Village, Musi Rawas Regency. This research is included in quantitative descriptive research, this study uses a survey method by taking samples of microalgae in the Barata Dam Area, E. Wonokerto Village, Musi Rawas Regency, then the sample is examined at the Biology Laboratory of STKIP-PGRI Lubuklinggau. Types of microalgae found in the Barata Dam, E. Wonokerto Village, Musi Rawas Regency, 3 Divisions, 5 Classes, 14 Orders, 15 families, 15 genera and 15 species. The data that has been obtained from the research is then analyzed using the formula (Shannon-winer). The results of the diversity index of microalgae species at station I are 2,479, at station II the diversity index is 2,550 and at station III the diversity index is 2,836, the average diversity index from the three stations is 2,622 the index is classified as moderate. The types of microalgae from the Bacillariophytaceae class consist of 6 species including: Synedra ulna, Cylotella sp., Asterionella sp., Surirella sp., Tablelaria sp., and Rhizosolenia sp., Chlorophyceae class consists of 6 species including: Pleurotaenium sp. , Spirogyra sp., Closteridium sp., Selenastrum sp., Pediastrum duplex, and Microspora sp., Trebouxiophyceae class consists of 1 species namely: Chlorella sp., Ulvophyceae class consists of 1 species namely: Ulothrix sp., and Chyanophyta class consists of of only 1 species, namely: Oscillatoria sp., Abiotic factors found in the Barata Dam Area, E. Wonokerto Village, Musi Rawas Regency, namely: temperature (water) with an average (27.6 C), pH (water) with an average (7.7) and brightness (water) with an average $(76.1 \mathrm{~cm})$.
\end{abstract}

Keywords: Diversity, Microalgae, Barata Dam

\section{PENDAHULUAN}

Indonesia merupakan salah satu negara yang memiliki keanekaragaman hayati yang sangat besar Husamah dkk (2017) memiliki iklim tropis yang terletak diatara dua benua dan 2 samudra, yaitu benua Asia dan Australia serta Samudra Hindia dan Samudra Pasifik dengan posisi $6^{\circ} \mathrm{LU}-$ $11^{\circ} \mathrm{LS}$ dan $95^{\circ} \mathrm{BT}$ dan $141^{\circ} \mathrm{BT}$. Indonesia mempunyai dua jalur pegunungan yang masih aktif, hal ini juga yang menyebabkan indonesia masih menjadi kawasan yang rawan terhadap gempa (Elizabeth, 2014). Secara biografis Indonesia tidak pernah bisa di pisahkan oleh kekayaan flora dan faunanya, Kondisi biografis Indonesia menyebabkan Indonesia mempunyai keanekaragaman yang sangat tinggi, di Indonesia mempunyai 1.500 jenis alga yang tersebar di perairan laut dan perairan air tawar (Elizabeth, 2014).

Salah satu Provinsi yang ada di Indonesia yang memiliki keanekaragaman ekosistem perairan yang sangat besar serta menjanjikan yaitu di Provinsi Sumatera Selatan, seperti terdapat banyaknya populasi yang berada di ekosistem perairan, air memiliki peran yang sangat penting bagi semua makhluk hidup, keberadaan ekosistem perairan dapat memberikan manfaat bagi makhluk hidup baik yang ada di perairan tersebut maupun di sekitarnya (Harmoko, 2017).

Desa E.Wonokerto adalah salah satu desa yang ada di Kabupaten Musi Rawas 
yang memiliki beberapa ekosistem perairan. Perarairan tersebut berupa sungai dan bendungan. Bendungan merupakan suatu bangunan yang dibuat dari pasangan batu kali, dan beton yang terletak melintang diatas sungai. Bendungan yang ada di Desa E.Wonokerto Kabupaten Musi Rawas merupakan salah satu Icone Desa yang di manfaatkan oleh masyarakat sekitar sebagai saluran irigas pertanian, tempat rekreasi, dan tempat pemancingan, bendungan tersebut mempunyai tinggi $\pm 5 \mathrm{M}$ dan lebar $\pm 10 \mathrm{M}$ (Mangore dkk, 2013).

Mikroalga atau ganggang adalah mikroorganisme perairan yang dapat memperoleh makanan dengan sendirinya karena mikroalga dapat melakukan fotosintesis dan hidup nutrien organik yang menghasilkan zat-zat organik melalui proses yang di sebut dengan fotosintesis (Imelda dkk, 2018). Mikroalga merupakan salah satu organisme perairan yang difungsikan sebagai bioindikator kualitas air suatu perairan. Konsentrasi klorofil yang terkandung di dalam sel mikroalga dapat di ukur untuk mengetahui tinggi rendahnya kelimpahan mikroalga pada suatu badan air (Hakiki, 2016).

Kondisi Bendungan Barata dan jenis-jenis Mikroalga yang ada di Bendungan tersebut, dari informasi yang di peroleh jenis mikroalga yang ada di Bendungan tersebut belum teridentifikasi, kondisi bendungan tersebut banyak di tumbuhi tanaman eceng gondok dan kurang pedulinya masyarakat setempat mengenai kelestarian bendungan Barata tersebut yang masih sering membuang sampah di Bendungan sehingga menyebabkan kondisi aliran air sering meluap sehinga menyebabkan banjir di lingkungan sekitar.

Keberadaan mikroalga juga terpengaruh oleh pencemaran lingkungan bendungan yang ada, oleh karena itu perlu dilakukan penelitian mengenai keberadaan jenis mikroalga yang ada di Bendungan Barata Desa E.Wonokerto Kabupaten Musi Rawas. Berdasarkan uraian diatas, maka peneliti tertarik untruk melakukan penelitian di Bendungan Barata Desa E.Wonikerta Kabupaten Musi Rawas, mengenai keanekaragaman mikroalga di Bendungan Barata Desa E.Wonokerto Kabupaten Musi Rawas

\section{METODE}

Penelitian ini merupakan jenis penelitian diskriptif kuantitatif (Nurohman dkk, 2015), data diperoleh dari penelitian dianalisis secara kuantitatif. Diskriptif kuantitatif yaitu suatu prosedur penelitian tradisional, metode ini sering disebut sebagai metode discovery karena metode ini peneliti dapat mengolah data berupa angka-angka dan analisis menggunakan statistik (Sugiyono, 2015).

Metode yang digunakan dalam penelitian ini yaitu metode survey dengan mengambil sampel mikroalga di kawasan Bendungan Barata, kemudian sampel tersebut diidentifikasi di Laboratorium STKIP-PGRI Lubuklinggau, yang bertujuan untuk mengetahui keanekaragaman jenis mikroalga yang ada di Kawasan Bendungan Barata Desa E.Wonokerto.

\section{HASIL DAN PEMBAHASAN}

Berdasarkan hasil penelitian yang telah dilakukan di kawasan Bendungan Barata Desa E. Wonokerto Kabupaten Muai Rawas, mengambil sampel air dan dengan menganalisis sampel air dari Bendungan Barata menggunakan mikroskop cahaya dengan perbesaran $10 \mathrm{X}$ 40 di temukan 4 Divisi, 5 Kelas, 14 Ordo, 15 Family, 15 Genus dan 15 spesies. 
Tabel 1

Tabel Perbandingan Mikroalga Yang Ada Di setiap setasiun Bendungan Barata Desa E.Wonokerto Kabupaten Musi Rawas

\begin{tabular}{|c|c|c|c|c|c|c|c|}
\hline \multirow[t]{2}{*}{ Divisi } & \multirow[t]{2}{*}{ Ordo } & \multirow[t]{2}{*}{ Family } & \multirow[t]{2}{*}{ Genus } & \multirow[t]{2}{*}{ Spesies } & \multicolumn{3}{|c|}{ Stasiun } \\
\hline & & & & & 1 & 2 & 3 \\
\hline \multirow{7}{*}{ Bacillariophyta } & Fragilariales & Flagilariaceae & Synedra & Synedra ulna & 11 & 9 & 3 \\
\hline & Stephanodiscales & Stephanodiscaceae & Cylotella & Cylotella $\mathrm{sp}$ & 3 & 3 & 3 \\
\hline & Eunotiales & Eunotiaceae & Asterionella & Asterionella $s p$ & 1 & 1 & 3 \\
\hline & Surirellales & Surirellaceae & Surirella & Surirella $\mathrm{sp}$ & 7 & 5 & 2 \\
\hline & Tabellariales & Tabellariaceae & Tabellaria & Tabellaria $s p$ & 7 & 6 & 4 \\
\hline & Biddulphiales & Rhizosoleniiceae & Rhizosolenia & Rhizosolenia sp & 2 & 4 & 4 \\
\hline & Zygnematales & Demidiaceae & Pleurotaenium & Pleurotaenium sp & 4 & 4 & 5 \\
\hline \multirow[t]{7}{*}{ Chlorophyta } & & Zygnemataceae & Spirogyra & Spirogyra sp & 7 & 9 & 4 \\
\hline & Chloroccales & Chloroccaceae & Closteridium & Closteridium sp & 1 & 3 & 2 \\
\hline & Sphaeropleales & Selenastracae & Selenastrum & Selenastrum sp & 8 & 2 & 7 \\
\hline & Chloroccales & Hydrodictyceae & Pediastrum & $\begin{array}{l}\text { Pediastrum } \\
\text { duplex }\end{array}$ & 10 & 2 & 4 \\
\hline & Ulothrichales & Microsporaceae & Microspora & Microspora $\mathrm{sp}$ & 1 & 1 & 1 \\
\hline & Oocystales & Chloroccaceae & Chlorella & Chlorella $\mathrm{sp}$ & 3 & 3 & 3 \\
\hline & Ulothrichales & Ulothrichaceae & Ulothrix & Ulothrix sp & 3 & 9 & 7 \\
\hline Chyanophyta & Oscillatoriales & Oscilatoriaceae & Oscillatoria & Oscillatoria $\mathrm{sp}$ & 12 & 7 & 4 \\
\hline
\end{tabular}

Tabel 2

Keanekaragaman Mikroalga di Bendungan Barata Desa E. Wonokerto Kabupaten Musi Rawas

\begin{tabular}{lccccc}
\hline No & Nilai & \multicolumn{3}{c}{ Stasiun } & Rata-rata \\
\cline { 3 - 5 } & & $\mathbf{1}$ & $\mathbf{2}$ & $\mathbf{3}$ & \\
1 & Keanekaragaman & 2.47 & 2.55 & 2.83 & 2.62 \\
2 & Dominansi & 0.09 & 0.09 & 0.10 & 0.09 \\
3 & Keseragaman & 1.32 & 1.63 & 2.16 & 1.70 \\
\hline
\end{tabular}

Berdasarkan Tabel 2 diatas dapat simpulkan bahwa keanekaragaman tertinggi berada pada stasiun 3 dengan nilai keanekaragaman sebesar 2.836 . Dominansi tertinggi berada pada stasiun 3 dengan nilai dominansi sebesar 0,103, Keseragaman tertinggi berada pada stasiun 3 dengan nilai 2,167. Penelitian ini dilakukan dalam 3 kali pengulangan dan mendapatkan 3 Divisi diantaranya yaitu: Bacillariophyta spesies yang ada pada divisi ini terdiri dari 6 spesies yaitu Synedra ulna, Cylotella sp., Asterionella sp., Surirella sp., Tabellaria sp.,

Tabel 3

Faktor Abiotik yang Ada di Bendungan Barata Desa E. Wonokerto Kabupaten Musi Rawas

\begin{tabular}{lccccc}
\hline No & Parameter & \multicolumn{3}{c}{ Stasiun } & Rata-Rata \\
\cline { 3 - 5 } & & $\mathbf{1}$ & $\mathbf{2}$ & $\mathbf{3}$ & \\
\cline { 3 - 5 } 1 & Suhu Air $\left({ }^{\circ} \mathrm{C}\right)$ & 27.4 & 27.7 & 27.6 & 27.6 \\
2 & $\mathrm{pH}$ (Air) & 7.8 & 7.7 & 7.6 & 7.7 \\
3 & Kecerahan Air $(\mathrm{Cm})$ & 76.3 & 76.7 & 75.3 & 76.1 \\
\hline
\end{tabular}

(C) 2021 Florea: Jurnal Biologi dan Pembelajarannya | 114
Rhizosolenia sp. yang mendominansi di pada semua stasiun I, II, dan III. Divisi Chlorophyta terdiri dari 7 spesies yaitu: Pleurotaenium sp., Spirogyra sp., Closteridium sp., Selenastrum sp., Pediastrum duplex, Microspora sp., Chlorella sp., Ulothrix sp. juga mendominansi pada semua stasiun I,II, dan III. Dan pada Divisi Chyanophyta hanya terdiri dari 1 spesies saja yaitu: Oscillatoria $\mathrm{sp}$. 
Berdasarkan tabel 3 diatas dapat dilihat bahwa suhu air yang terdapat di Kawasan Bendungan Barata Desa E. Wonokerto Kabupaten Musi Rawas dari ketiga stasiun dalam pengambilan sampel penelitian di temukan perbedaan diantara pengukuran yang pertama, kedua dan yang ketiga. Hasil dari pengukuran suhu tersebut pada ketiga stasiun mendapatkan rata-rata $27.6{ }^{\circ} \mathrm{C}$, dan suhu yang tertinggi berada pada stasiun 2 dengan suhu Air $27.7{ }^{\circ} \mathrm{C}$.

Hasil pengukuran $\mathrm{pH}$ air pada masing-msaing stasiun juga mendapatkan hasil yang berbeda juga masih dalam keadaan yang stabil yaitu dengan rata-rata 7.7 hal ini menandakan bahwa tidak adanya perubahan $\mathrm{pH}$ yang ekstrim pada stiap stasiun. Hasil dari pengukuran kecerahan air pada ketiga stasiun mempunyai perbedaan sehingga di peroleh rata-rata $76.1 \mathrm{~cm}$, dengan kecerahan tertinggi berada pada stasiun ke 2 dengan nilai 76.7 kondisi air yang ada adi Bendungan Barata tersebut berwarna sedikit kecoklatan.

Hasil penelitian yang sudah dilaksanakan di kawasan Bendungan Barata Desa E. Wonokerto Kabupaten Musi Rawas dengan 3 stasiun yaitu terdiri dari 3 Divisi yang terdiri dari Bacillariophyta, Chlorophyta dan Chyanophyta, 5 kelas yaitu: Bacillariophytaceae, Chlorophyceae, Trebouxiophyceae, Ulvophyceae dan Cyanophyceae, 14 ordo yaitu: Fragilariales, Stephanodiscales, Eunotiales, Surirellales, Tabellariales, Biddulphiales, Zygnematales, Chloroccales, Sphaeropleales, Chloroccales, Ulothrichales, Oocystales, Ulothrichales, dan Oscillatoriales. 15 Family yaitu: Flagilariaceae, Stephanodiscaceae, Eunotiaceae, Surirellaceae, Rhizosoleniiceae, Zygnemataceae, Selenastracae, Microsporaceae,
Ulothrichaceae, dan Oscilatoriaceae. 15 Genus yaitu: Synedra, Cylotella, Asterionella, Surirella, Tabellaria, Rhizosolenia, Pleurotaenium, Spirogyra, Closteridium, Selenastrum, Pediastrum, Microspora, Chlorella, Ulothrix, dan Oscillatoria. Dan 15 spesies yaitu: Synedra ulna, Cylotella sp., Asterionella sp., Surirella sp., Tabellaria sp., Rhizosolenia sp., Pleurotaenium sp., Spirogyra sp., Closteridium sp., Selenastrum sp., Pediastrum duplex, Microspora sp., Chlorella sp., Ulothrix sp., dan Oscillatoria $\mathrm{sp.}$

Divisi Bacillariophyta yang di temukan di kawasan Bendungan Barata Desa E. Wonokerto Kabupaten Musi Rawas terdiri dari 6 spesies yaitu: Synedra ulna, Cylotella sp., Asterionella sp., Surirella sp., Tabellaria sp., Rhizosolenia sp.. Misra (2012) Menyatakan bahwa Divisi Bacillariophyta dapat hidup bergantung pada kualitas senyawa kimia yang ada di ada di suatu perairan.

Andriansyah, dkk (2014) menyebutkan bahwa divisi Bacillariophyta dapat beradaptasi disemua kondisi aliran air karena pada divisi Bacillariphyta ini memiliki alat penempel yang kuat berupa tungkai bergelatin. Jumlah spesies pada divisi Bacillariphyta yang di temukan di sungai kelingi lebih banyak di bandingkan dengan yang di temukan di danau aur, hal ini di karenakan kondisi lingkungan sungai kelingi mendukung untuk untuk kehidupan divisi Bacillariophyta.

Divisi Chlorophyta yang di temukan di Kawasan Bendungan Barata Desa E. Wonokerto Kabupaten Musi Rawas terdiri dari 8 spesies diantaranya yaitu: Pleurotaenium sp, Spirogyra sp, Closteridium sp, Selenastrum sp, Pediastrum duplex, Microspora sp, Chlorella sp dan Ulothrix sp. Menurut Sari (2018:61) menyatakan bahwa Divisi Chlorophyta memiliki kemampuan untuk menyesuaikan diri terhadap arus yang kuat maupun lambat karena divisi Chlorophyta ini memiliki alat penempel pada substrai 
berupa tungkai yang bergelatin. Kondisi lingkungan yang kurang baik atau tercemar dapat menyebabkan mikroalga divisi Chlorophyta akan berkembang biak dengan cepat sehingga akan menyebabkan bloming alga/jumlah alga yang ada di suatu perairan tersebut akan banyak (Harmoko \& Sepriyaningsih, 2018).

Prasetyo dkk (2013) menyatakan bahwa semakin tinggi tingkat keanekaragaman divisi Chlorophyta di suatu perairan dapat diartikan bahwa perairan tersebut tergolong dalam pencemaran tingkat sedang. Ciri umum dari divisi Chlorophyta ini berwarna hijau dan mengandung pigmen klorofil (Fauziah \& Lily 2015). Divisi Chlorophyta di temukan di ketiga stasiun penelitian, hanya saja pada setiap stasiun jumblah yang di temukan berbeda, jumlah spesies dari divisi Chlorophyta yang tertinggi berada pada stasiun 1 dengan jumlah 40.

Harmoko, dkk (2018) Divisi Cyanophyta hidup dengan cara menempel di permukaan substrat dan biasanya divisi ini hidup menempel pada tumbuhan dan terkdang hidup sebagai plantonik, Pada penelitian yang telah dilakukan di Bendungan Barata Desa E. Wonokerto Kabupaten Musi Rawas mikroalga divisi Cyanophyta hanya ditemukan satu spesies saja yaitu Oscillatoria sp. Divisi Cyanophyta mepunyai spesies dengan nama Oscillatoria sp, spesies ini mempunyai ciri-ciri berwarna hijau kebiruan, bentuk yang panjang serta ada yang hidup tunggal dan juga ada yang hidup secara berkelompok (Purwantoro, 2014).

Divisi Cyanophyta di kawasan Bendungan Barata Desa E. Wonokerto Kabupaten Musi Rawas hanya ditemukan satu spesies saja hal ini disebabkan suhu yang dibutuhkan oleh Divisi Cyanophyta ini lebih tinggi dari kisarah suhu yang dibutuhkan (Andriansyah, dkk, 2014). Suhu (Air) yang diperoleh pada penelitian yang telah di lakukan di Bendungan Barata
Berkisar 27,6 ${ }^{\circ} \mathrm{C} \quad$ sehingga Divisi Cyanophyt jarang di temukan.

Berdasarkan hasil penelitian Keanekaragaman Mikroalga di kawasan Bendungan Barata Desa E.Wonokerto Kabupaten Musi Rawas, keaenekaragaman mikroalga dapat di lihat pada Tabel 2 Tingkat keanekaragaman mikroalga di Bendungan Barata mempunyai nilai 2,622 dengan kriteria "Keanekaragaman Sedang", Keanekaragaman mikroalga berada pada stasiun 3 dengan indeks keanekaragaman 2,836, keanekaragaman terendah berada pada stasiun I dengan indeks keanekaragaman 2,479 indeks keanekaragaman mikroalga ini termasuk dalam kategori keanekaragaman sedang,dengan nilai rata-rata pada ketiga stasiun yaitu 2,622 yang termasuk dalam kriteria "Keanekaragaman Sedang" (Harmoko \& Sepriyaningsih, 2019). Keanekaragaman mikroalga yang ada di suatu perairan dapat menggambarkan ataupun dapat memberikan informasi mengenai tingkat pencemaran air pada suatu perairan (Wibowo, dkk, 2009).

Indeks dominansi (C) berdasarkan hasil penelitian yang telah dilakukan indeks dominansi digunakan untuk melihat tingkat dominansi dari suatu biota tertentu. Nilai indeks dominansi bekisarsekitar 0-1 (Nurhasanah, 2014), jika ditemukan nilai indeks dominansi 1-0 maka dapat di simpulkan bahwa spesies tersebut mendominansi spesies lainnya, dan apabila indeks dominansi mendekati 0 maka dapat disimpulkan bahawa kondisi pada perairan tersebut tidak ada spesies yang mendominansi dan biasanya sering dijumpai dengan indeks keseragaman (E) tinggi (Harmoko \& Sepriyaningsih, 2019).

Nilai indeks dominansi yang terdapat di kawasan Bendungan Barata Desa E. Wonokerto Kabupaten Musi Rawas memiliki nilai rata-rata sebesar 0,097 dengan kriteria "tidak ada dominansi/tidak ada spesies yang mendominansi", nilai tersebut tergolong pada indeks dominansi yang rendah. 
Namun demikian, pada setiap stasiun masih di temukan beberapa spesies yang sering muncul salah satunya yaitu Synedra ulna dan Oscillatoria sp.

Indeks Keseragaman

merupakan salah satu indeks yang digunakan dalam penelitian keanekaragaman, indeks keseragaman ini merupakan suatu indeks yang dapat menggambarkan penyebaran dari suatu individu antar spesies yang berada dan diperoleh dari hubungan keanekaragaman $\left(H^{\prime}\right)$ dengan keseragaman maksimal. Indeks ini menggambarkan suatu penyebaran individu antar spesies yang berbeda dan di peroleh dari hubungan antara keanekaragaman (H') dan keseragaman maksimalnya (Harmoko \& Sepriyaningsih, 2019). Nilai dari Indeks keseragaman ini berkisar antara 0-1 (Nurhasanah, 2014).

Berdasarkan hasil perhitungan yang telah dilakukan pada penelitian di kawasan Bnedungan Barata Desa E. Wonokerto Kabupaten Musi Rawas nilai Indeks keseragaman rata-rata yang di peroleh yaitu 1.709, hal ini dapat disimpulkan bahwa keseragaman mikroalga yang ada di Bendungan Barata tersebut "Spesies mendominasi spesies lainnya". Indeks keseragaman tertinggi berada pada stasiun 3 dengan nilai 2.167 , dan indeks keseragaman terendah berada pada stasiun 1 dengan nilai indeks keseragaman yaitu 1.324.

Berdasarkan hasil penelitian yang telah di lakukan di Bendungan Barata Desa E. Wonokerto Kabupaten Musi Rawas, parameter yang di ukur terdiri dari 3 jenis, Suhu (Air) pengukuran ini dilakukan untuk mengukur suhu air yang ada di kawasan Bendungan Barata alat ukur yang digunakan yaitu thermometer. pH (Air) pengukuran ini dilakukan untuk mengetahui keasaman dari air yang ada di Bendungan Barata, alat ukur yang digunakan yaitu $\mathrm{pH}$ meter dan pengukuran Kecerahan (Air) dilakukan untuk mengukur kecerahan air yang ada di
Bendungan Barata, Alat ukur yang di gunakan yaitu secchi disk.

Berdasarkan hasil pengukuran tersebut diperoleh nilai rata-rata suhu (air) $27.6{ }^{\circ} \mathrm{C}, \mathrm{pH}$ (air) 7.7 dan kecerahan (air) $76.1 \mathrm{~cm}$, hal tersebut menghasilkan nilai berbeda pada stiap masing-masing stasiun dan pengulangan. Suhu adalah salah satu faktor penting dalam lingkungan untuk mendukung kehidupan dari suatu makhluk hidup (Harmoko dan Krisnawati, 2018). Suhu merupakan parameter penting bagi kehidupan makhluk hidup air, karena suhu dapat mempengaruhi aktivitas metabolisme kehidupan dan perkembangan diri organisme perairan. Sari dkk (2013) menyatakan bahwa suhu optimum untuk kehidupan mikroalga berkisar $30{ }^{\circ} \mathrm{C}$. Menurut Astuti,dkk (2012) menyatakan bahwa suhu kisaran untuk mikroalga hidup dan berkembangbiak sekitar 20-30 ${ }^{\circ} \mathrm{C}$. Dapat disimpulkan bahwa dari hasil penelitian yang telah dilakukan di kawasan Bendungan Barata Desa E. Wonokerto Kabupaten Musi Rawas berada pada kisaran yang normal untuk di tempati mikroalga karena suhu (air) rata-rata yang ada di Bendungan Barata senilai $27.6^{\circ} \mathrm{C}$.

$\mathrm{pH}$ atau derajat keasaman merupakan salah satu dari pencerminan keseimbangan asam dan basa yang ada di suatu perairan (Sari, 2014). Prasetyo (2013) menjelaskan bahwa pH merupakan nilai dari suatu konsentrasi ion hidrogen yang ada di dalam air, nilai $\mathrm{pH}$ juga di pengaruhi oleh beberapa parameter antara lain yaitu, suhu, kandungan oksigen dan konsentrasi ion-ion. Menurut Kawaroe (2010) menyatakan bahwa $\mathrm{pH}$ atau derajat keasaman normal itu berkisar 6,5-8,5. Berdasarkan hasil pengukuran yang telah dilakukan di lokasi penelitian didapatkan rata-rata $\mathrm{pH}$ (air) yaitu 7.7 hal ini menandakan bahwa $\mathrm{pH}$ (air) yang ada di Bendungan Barata Desa E. Wonokerto Kabupaten Musi Rawas berada pada kisaran normal. 
Arfah dkk (2016) menjelaskan bahwa kecerahan air merupakan salah satu faktor penting dalam kehidupan biota air, sedangkan menurut Prasetyo (2013) kecerahan perairan di bedakan menjadi 3 macam yaitu, apabila nilai kecerahan mencapai 0,25-1 m ini merupakan suatu kondisi bahwa air tersebut keruh, apabila kecerahan air dapat mencapai 1,5 m mempunyai nilai sedikit keruh dan apabila

\section{SIMPULAN}

Tingkat keanekaragaman Mikroalga yang ada di Bendungan Barata Desa E.Wonokerto Kabupaten Musi Rawas di bagi menjadi 3 stasiun. Stasiun I di dapatkan keanekaragaman mikroalga dengan indeks rata-rata 2.622 indeks keanekaragaman tersebut tergolong sedang. Analisis perhitungan selanjutnya yaitu indeks dominasi mikroalga mempunyai rata-rata sebesar 0.097 indeks dominansi tersebut tergolong sedang. Analisis perhitungan ketiga yaitu indeks keseragaman dengan rata-rata yang di peroleh sebesar 1.709 indeks keseragaman tersebut tergolong sedang.

Faktor abiotik yang terdapat di Bendungan Barata Desa E. Wonokwero Kabupaten Musi Rawas, di kawasan penelitian memiliki rata-rata suhu air sebesar $27.6{ }^{\circ} \mathrm{C}$, rata-rata $\mathrm{pH}$ air yang di peroleh sebesar 7.7 dan rata-rata kecerahan air yang di peroleh sebesar $76.1 \mathrm{~cm}$.

\section{DAFTAR PUSTAKA}

Amini, A. \& Susilowati, R. (2010). Produksi Biodisel dari Mikroalga Botcryococcus brauni. Jurnal Squalen. 5 (1), 23-29.

Analia, F. (2018). SKRIPSI. Inventarisasi Mikroalga Di Sungai Malus Kecamatan Lubuklinggau Utara Kota Lubuklinggau. Skripsi Pendidikan Biologi STKIP-PGRI Lubuklinggau.

Andriansyah., Setyawati, R, T., \& Lovandi, I. (2014). Kualitas Perairan Kanal Sungai Jawi dan Sungai Raya kondisi suatu perairan tersebut mencapai lebih dari $5 \mathrm{~m}$ maka dapat diartikan bahwa kondisi perairan tersebut sangat cerah. Bedaarkan pengukuran yang telah dilakukan di Kawasan Bendungan Barata Desa E. Wonokerto Kabupaten Musi Rawas memiliki kecerahan dengan ratarata $76,1 \mathrm{~cm}$ dengan kondisi air sedikit keruh.

Dalam Kota Pontianak Ditinjau dari Struktur Komunitas Mikroalga Perifitik. Jurnal Protobiont, 3 (1), 61-70.

Anggraini, R. (2018). SKRIPSI. Inventarisasi Mikroalga di air Terjun Sei Sando Kecamatan Lubuklinggau. Skripsi Pendidikan Biologi STKIP-PGRI Lubuklinggau.

Arfah, H., Simon.,\& Patty. (2016). Kualitas Air dan Komunitas Makroalga Di Perairan Pantai Jekumerasa, Pulau Buru. Jurnal Ilmiah Platax, 4(2), 109-119.

Astuti, P, R., (2012). Kelimpahan Beberapa Jenis Mikroalga Diatom Di Perairan Pulau GumilamoMagaliho, Halmahera Utara. Jurnal Ilmu dan Teknologi Kelautan Tropis, 4(1), 97-106.

Belcher, H \& E. Swale. (1978). A. Beginner's Guide To Fresh Water Algae. London: Institute Of Terestrial Ecology.

Bellinger, H.G \& S.C. David. (2001). Freshwater Algae. London: Jhon Wily dan Sons.

Biggs, B, J, F \& Cathy. (2000). Stream Pheriphyton Monitoring Manual. New Ziland: Niwa.

Botes, L. (2003). Phytoplankton Identification Cataloque saldanha bay, South Africa, April 2001. GloBallast Monograph Series No. 7. IMO London.

Elizabeth. (2014). Kekinian Keanekaragaman Hayati Indonesia. Jakarta: LIPI Pres. 
Fauziah, M, H \& Laily, N, A. (2015). Identifikasi Mikroalga Dari Divisi Chlorophyta Di Waduk Sumber Air Jaya Dusun Krebet Kecamatan Bululawang Kabupaten Malang. Jurnal Bioedukasi, 8(1), 20-22.

Harmoko \& Sepriyaningsih. (2017). Keanekaragaman Mikroalga di Sungai Kati Kota Lubuklinggau. Jurnal Scripta Biologica, 4 (3), 201-205.

Harmoko \& Sepriyaningsih. (2019). Bioindikator Sungai Dengan Mikroalga. Yogyakarta: CV Budi Utama.

Harmoko \& Sepriyaningsih. (2020). Keanekaragaman Mikroalga Chlorophyta di Sungai Kasie Kota Lubuklinggau Provinsi Sumatera Selatan. Quangga Jurnal Pendidikan Biologi, 12 (1): 51-56.

Harmoko \& Sepriyaningsih. (2018). Keanekaragaman Mikroalga Chlorophyta di Sungai Kelingi Kota Lubuklinggau Sumatera Selatan. Jurnal Pro-Life, 5 (3): 666-676.

Harmoko., Lokaria, E., \& Misra, S. (2017). Eksplorasi Mikroalga di Air Terjunn Watervang Kota Lubuklinggau. Bioedukasi Jurnal Pendidikan. 8 (1), 75-82. DOI: 10.24127/bioedukasi.v8i1.840.

Harmoko., Lokaria, E., \& Anggraini, R. (2019). Keanekaragaman Mikroalga di Air terjun sando kota lubuklinggau, sumatera selatan. LIMNOTEK Perairan Darat Tropis di Indonesia. 26(2), 77-87.

Harmoko \& Yuni Krisnawati., (2018). Mikroalga Divisi Bacillariophyta Yang Di Temukan Di Danau Aur Kabupaten Musi Rawas. Jurnal biologi Universitas Andalas, 6(1), 30-35.

Hakiki, R.(2016). Mikroalga Sebagai Bioindikator Kualitas Air Permukaan. Journal Of Evn.
Engineering \& Waste

Managemen.1(1), 46-54.

Husamah., Rahardjanto, A., \& Hudha, M, A. (2017). Ekologi Hewan Tanah. Malang: Universitas Muhamadiyah Malang.

Imelda, S., Claudia, C., Lambui, O.,\& Suwastika, N, I. (2018). Kultivasi Mikroalga Isolat Lokal Pada Medium Ekstrak Tauge Cultivation Of Local Microalga Isolate On Bean Sprouts Extract Medium. Jurnal Of Science And Technology, 7 (2), 148-157.

Kasrina., Irawati, S., Jayanti, E, W. (2012). Ragam Jenis Mikroalga Di Air Rawa Kelurahan Bentiringin Permai Kota Bengkulu Sebagai Sumber Belajar Biologi SMA. Jurnal Exacta. 5 (1), 36-44.

Khotimah, K. (2018). Membangun Ketahanan Energi Pendukung Pertahanan Maritim Melalui Pemanfaatan Mikroalga Sebagai Biodisel Bagi Masyarakat Pesisir. Jurnal Pertahanan Dan Bela Negara,8 (1), 67-84.

Mangore, R, V., Wuisan, M, E., \& Tengkudung, H, K. (2013). Rencana Bendungan Untuk Daerah Irigasi Sulu. Jurnal Sipil Statistik, 1 (7), 533-541.

Merlia, R. (2017). Inventarisasi Berbagai Jenis Mikroalga di Sungai Kelingi Kecamatan Lubuklinggau. Skripsi Pendidikan Biologi STKIP-PGRI Lubuklinggau.

Mudatsir. (2007). Faktor-faktor Yang Mempengaruhi Kehidupan Mikroba Dalam Air. Jurnal Kedokteran Syiah Kuala, 7 (1), 23-30.

Mulyono, J. (2017). Konsepsi keamanan bendungan dalam pembangunan dan pengelolaan bendungan. Jurnal Infrastruktur, 3 (1), 62-69.

Nurhasanah. (2014). Keanekaragaman Mikroalga Di Balai Budidaya Air Tawar (Bbat) Kecamatan Sungai 
Gelam Jambi. SKRIPSI Pendidikan Biologi Universitas Jambi.

Nurohman, E., Rahardjanto, A., \& Wahyuni, S. (2015). Keanekaragaman Mikrofauna Tanah Di Kawasan Perkebunan Coklat (Theobroma cacao L) Sebagai Bioindikator Kesuuran Tanah dan Sumber Belajar Biologi. Jurnal Pendidikan Biologi Indonesia, 1(2),197-208).

Peraturan Pemerintah Republik Indonesia Nomor 37 Tahun 2010 Tentang Bendungan.

Prayitno, A, T. \& Hidayati, N. (2017). Pengantar Mikrobiologi. Malang: Media Nusa Creative.

Prasetyo, B \& Kusumaningrum, N, E. (2013). Lingkungan Fisik Dan Kekayaan Mikroalga Di Danau Universitas Terbuka, Tanggerang Selatan. Jurnal Matematika Sains dan Teknologi, 14(2), 119-127.

Prihantini, N, B.,Wardhana, W., Hendrayanti, D., Widyawan, A., Ariyani, Y., \& Rianto, R. (2008). Biodiversitas Cyanobacteria Situ/Danau di Kawasan JakartaDepok-Bogor, Indonesia. Jurnal Makara Sains, 12 (1), 44-54.

Puspitasari, R. \& Lestari. (2014). Chaetoceros gracilis Sebagai Bioindikator Kualitas Sedimen. Jurnal Ilmu Teknologi Kelautan Tropis, 6 (1), 187-196.

Rasid, A. (2004). Berbagai Manfaat Alga. Jurnal Oseana, XXIX(3), 9-15.

Rusdiani, R, R., Boedisantoso, R., \& Hanif, M. (2016). Optimalisasi Teknologi Fotobioreaktor Mikroalga Sebagai Dasar Perencanaan Strategi Mitigasi Gas. Jurnal Teknik ITS, 5 (2), 188-192.

Rukminasari, N., Nadiarti., \& Awaludin, K. (2014). Pengaruh Derajat Keasaman (pH) Air Laut Terhadap Konsentrasi Kalsium dan Laju Pertumbuhan Halimeda Sp. Jurnal Ilmu Kelautan dan Perikanan, 24 (1), 28-34.
Sari, M, R., Ngabekti, S., \& Martin, P, F. (2013). Keanekaragaman Fitoplanton Di Sumber Air Panas Condrodimuko Gendongsongo Kabupaten Semarang. Unnes Jurnal Of Life Scince, 2(2), 9-15.

Sari, P. (2018). SKRIPSI. Inventarisasi Mikroalga Di Air Terjun Satan Desa Muara Beliti Baru Kabuoaten Musi Rawas. Skripsi Pendidikan Biologi STKIP-PGRI Lubuklinggau.

Samudra, R, S., Soeprobowati, R, T., \& Izati, M. (2013). Komposisi Kelimpahan dan Keanekaragaman Fitiplanton Danau Rawa Pening Kabupaten Semarang. Jurnal Bioma, 15 (1), 6-15.

Setiawati, D. (2020). Keanekaragaman Serangga Permukaan Tanah Di Kawasan Bukit Gatan Kabupaten Musi Rawas. Skripsi Pendidikan Biologi STKIP-PGRI Lubuklinggau

Subandi. (2014). Mikrobiologi. Bandung: PT Remaja Rosdakarya.

Sugiyono. (2016). Metode Penelitian Kuantitatif, Kualitatif dan $R \& D$. Bandung: Alfabeta.

Sulastri. (2018). Fitoplanton Danau-danau di Pulau Jawa. Jakarta: Lipi Press.

Wibowo, E, P, H., Purnomo, T., Ambarwati, R.(2014). Kualitas Perairan Sungai Bengawan Solo Di Wilayah Kabupaten Bonjonegoro Berdasarkan Indeks Keanekaragaman Plankton. Ejurnal LenteraBio, 3(3), 209-215.

Wigati, R., Soedarsono., \& Rizki, F. (2016). Kaji Ulang Bendungan Tetap Cipas (Studi Kasus Desa Bunihara Kecamatan Anyer) Serang Banten. Jurnal Fondasi, 5 (2), 62-73. 